Check for updates

Cite this: RSC Adv., 2019, 9, 36213

Received 22nd August 2019

Accepted 29th October 2019

DOI: 10.1039/c9ra06596b

rsc.li/rsc-advances

\section{Blue light photoredox-catalysed acetalation of alkynyl bromides $\uparrow$}

\author{
Xue-Li Lyu, ${ }^{\text {a }}$ Shi-Sheng Huang, ${ }^{a}$ Hong-Jian Song, ${ }^{* a}$ Yu-Xiu Liu (D) *a \\ and Qing-Min Wang (D) *ab
}

Herein, we report an organo-photoredox-based protocol using 2,2-diethoxyacetic acid as the acetal source to achieve acetalation of alkynyl bromides to afford various alkynyl acetal products. In addition to arylethynyl bromides, substrates bearing heteroaryl rings (thiophene, pyridine, and indole) smoothly gave the corresponding acetalation products. This mild protocol has potential utility for the synthesis of aldehydes by further protonization.
Acetals play a key role in several biological interactions, ${ }^{1,2}$ and they are widespread in natural products obtained from various sources, including insects, marine organisms, fungi, plants, and microbes. ${ }^{2}$ In addition, reports of acetal-containing drugs have recently appeared in the literature, ${ }^{3}$ and acetals are frequently used to protect carbonyl groups during complex synthesis $^{4}$ (Fig. 1). Therefore, the development of new methods for the introduction of acetal moieties is highly desirable, and environmentally friendly methods are of particular interest.

In light of the growing demand for environmentally benign synthetic methods, visible-light-induced catalysis has recently garnered substantial attention in organic synthesis owing to its mild conditions and low energy requirements. ${ }^{5}$ For example, photoredox-catalyzed decarboxylation of alkyl carboxylic acids has become an important method for generating alkyl radicals. ${ }^{6}$ During decarboxylation of carboxylic acids and their derivatives under photoredox conditions, a C-centered radical can be generated via two complementary pathways: (a) a reductive quenching process in which the carboxylic acid transfers an electron to the excited-state photocatalyst to generate a Ccentered radical after $\mathrm{CO}_{2}$ extrusion ${ }^{7}$ and (b) an oxidative quenching process in which carboxylic acid derivatives such as $N$-(acyloxy)phthalimides accept an electron from the excitedstate photocatalyst to form a C-centered radical after extrusion of $\mathrm{CO}_{2}$ and a phthalimide anion (Scheme 1). ${ }^{8}$ This photoredoxcatalyzed radical decarboxylative functionalization offers a novel and efficient method for constructing $\mathrm{C}-\mathrm{C}$ and $\mathrm{C}-\mathrm{X}$ bonds. ${ }^{9}$ Recently, Xu and co-workers ${ }^{10}$ developed a protocol for iridium-photoredox-catalyzed decarboxylative conjugated

${ }^{a}$ State Key Laboratory of Elemento-Organic Chemistry, Research Institute of Elemento-Organic Chemistry, College of Chemistry, Nankai University, Tianjin 300071, People's Republic of China. E-mail:wangqm@nankai.edu.cn

${ }^{b}$ Collaborative Innovation Center of Chemical Science and Engineering (Tianjin), Tianjin 300071, People's Republic of China

$\dagger$ Electronic supplementary information (ESI) available. See DOI: 10.1039/c9ra06596b addition reactions between glyoxylic acid acetals and Michael acceptors; theirs was the first report of the introduction of acetal moieties via oxidative decarboxylation.

Herein, we report an organo-photoredox-based protocol for acetalation of alkynyl bromides, using 2,2-diethoxyacetic acid as the acetal source and 2,4,5,6-tetra $(9 \mathrm{H}$-carbazol-9-yl) isophthalonitrile (4CzIPN) as the photocatalyst. Aldehydes are reactive and therefore need to be protected against oxidation and reduction, and our operationally simple protocol provides direct access to protected aldehydes without producing large amounts of chemical waste. Considering its mild, metal-free conditions, the protocol has a considerable potential utility for the synthesis of alkynyl acetals.

We carried out reactions using alkynyl bromide $1 \mathrm{~g}$ and 2,2diethoxyacetic acid 2 as model reactants to optimize the conditions. When using 4CzIPN as a photocatalyst, irradiation of the substrates with $5 \mathrm{~W}$ blue LEDs at room temperature in the presence of $\mathrm{Cs}_{2} \mathrm{CO}_{3}$ under argon for $24 \mathrm{~h}$, we delighted to obtain the desired product $3 \mathrm{~g}$ in $57 \%$ yield (see the ESI $\uparrow$ for details). Next, we varied the reaction parameters with the goal of optimizing the yield. Through control experiment, we found $4 \mathrm{CzIPN}$, a blue LEDs, $\mathrm{Cs}_{2} \mathrm{CO}_{3}$, argon and $\mathrm{Br}$ as the leaving group

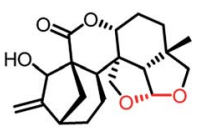

Macrocalyxoformin A

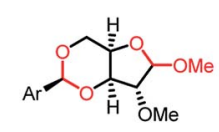

3,5-O-arylidene- $D$-xyloses

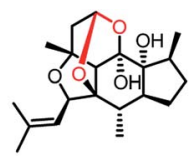

(+)-Norleucosceptroid A

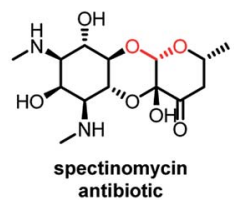

Fig. 1 Representative compounds containing acetal moieties. 


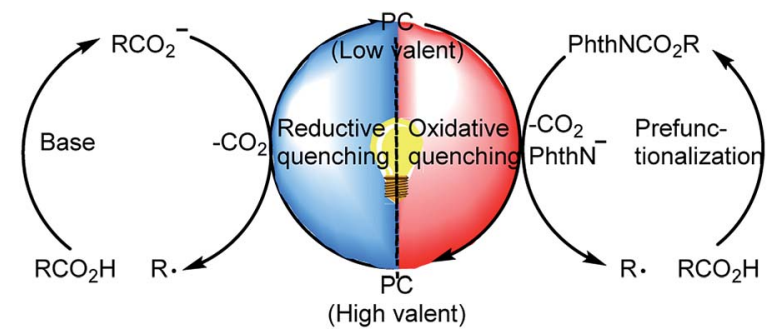

Scheme 1 Decarboxylation of alkyl carboxylic acids and their derivatives via photoredox catalysis.

were all indispensable. Even though benziodoxole-substituted alkynes are known to act as electrophilic alkyne acceptors, ${ }^{11}$ we found that an alkyne in which the $\mathrm{Br}$ atom was replaced with a benziodoxole moiety did not undergo addition of the acetal radical. By screening other photocatalysts, we found that 4CzIPN, which is a carbazole-based sensitizer reported by Zhang $^{12 a}$ and Adachi, ${ }^{12 b}$ was optimal. The high reduction potential of photoexcited $4 \mathrm{CzIPN}\left(E_{\mathrm{red}}\left[\mathrm{PC}^{*} / \mathrm{PC}^{\cdot-}\right]=+1.35 \mathrm{~V} v s\right.$. SCE $)^{12 a}$ makes it suitable for promoting photo-oxidative decarboxylation reactions. $\operatorname{Ir}\left[\left(\mathrm{dF}\left(\mathrm{CF}_{3}\right) \text { ppy }\right)_{2}(\mathrm{dtbbpy})\right] \mathrm{PF}_{6}\left(E_{\text {red }}\left[\operatorname{Ir}^{\mathrm{III} * /}\right.\right.$ $\left.\mathrm{Ir}^{\mathrm{II}}\right]=+1.21 \mathrm{~V} v$ s. SCE) also catalyzed the reaction, although the yield was substantially lower than that with 4CzIPN. Two other metallaphotoredox catalysts, $\mathrm{Ru}(\mathrm{bpy})_{3} \mathrm{Cl}_{2} \cdot 6 \mathrm{H}_{2} \mathrm{O}$ and $\mathrm{Ru}(\mathrm{bpy})_{3}(-$ $\left.\mathrm{PF}_{6}\right)_{2}$, were screened and found to be ineffective, perhaps because the low oxidation potentials $\left(E_{\text {red }}\left[\mathrm{Ru}^{\mathrm{II} *} / \mathrm{Ru}^{\mathrm{I}}\right]=+0.77 \mathrm{~V}\right.$ vs. SCE) of their excited states prevented them from promoting the decarboxylation reaction. Reaction in MeCN alone or DMF alone gave a lower yield than reaction in the $1: 1(\mathrm{v} / \mathrm{v}) \mathrm{MeCN} /$ DMF. Finally, $\mathrm{Cs}_{2} \mathrm{CO}_{3}$ was a better base than $\mathrm{Na}_{2} \mathrm{CO}_{3}$ or $\mathrm{K}_{2} \mathrm{CO}_{3}$.

Using the optimal conditions, we explored the substrate scope of the reaction with respect to the alkynyl bromide and found that a broad range of functional groups were tolerated (Scheme 2). Specifically, substrates with electron-donating groups on the aromatic ring of the alkynyl bromide gave moderate yields $(34-64 \%)$ of the expected products $(3 \mathbf{a}-3 \mathbf{k})$ upon reaction with 2. For example, reactions of phenylacetylene bromides with $\mathrm{Me}$, Et, ${ }^{n} \mathrm{Pr},{ }^{n} \mathrm{Bu},{ }^{t} \mathrm{Bu}$, and $\mathrm{Ph}$ groups at the para position of the benzene ring afforded $\mathbf{3 b} \mathbf{b} \mathbf{3 g}$, respectively. Some heteroatom-containing electron-donating groups were also explored. In addition to a methoxy group (3h), a 3,4-methylenedioxy group, a 3,4-ethylenedioxy group were acceptable, and acetals $3 \mathbf{i}$ and $3 \mathbf{j}$, respectively, were obtained in $43 \%$ yield. A phenylacetylene bromide with an amide-substituted benzene ring also reacted smoothly, giving a $49 \%$ yield of $3 \mathbf{k}$. Next we examined compounds with halogen-substituted benzene rings. Phenylacetylenes with a para $\mathrm{F}$ or $\mathrm{Br}$ atom, could give $\mathbf{3 m}$ and $\mathbf{3 q}$ in $44 \%$ and $49 \%$ yields, respectively. 2,2-Diethoxyacetic acid also reacted with ortho-, meta-, and para-Cl-substituted phenylacetylene bromides to afford desired products $\mathbf{3 n}-\mathbf{3 p}$ in $48^{-}$ $55 \%$ yields. Substrates with strongly electron-withdrawing $\mathrm{CF}_{3}$ $(3 \mathbf{r}, 42 \%)$ and $\mathrm{CN}(3 \mathbf{s}, 43 \%$ and $3 \mathbf{t}, 55 \%)$ substituents on the benzene ring were satisfactory as well, and the location of the CN group slightly affected the yield: the ortho-substituted compound gave a higher yield (55\%) than the para-substituted

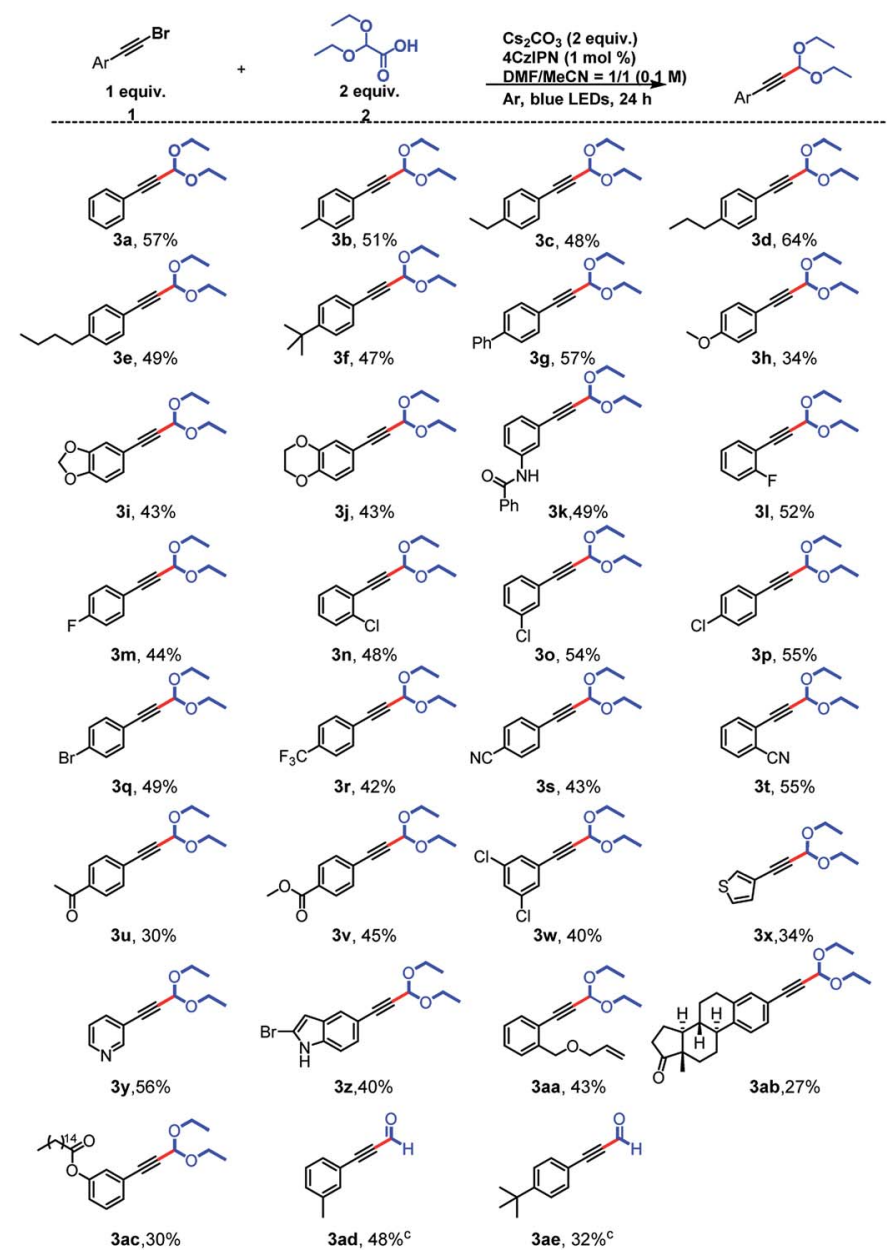

Scheme 2 Scope of the reaction with respect to the alkynyl bromide. aStandard conditions: a mixture of $1 \mathrm{~g}(0.3 \mathrm{mmol}, 1.0$ equiv.), 2 (0.6 mmol, 2.0 equiv.), 4CzIPN (0.003 mmol, $1 \mathrm{~mol} \%$ ), and $\mathrm{Cs}_{2} \mathrm{CO}_{3}$ (0.6 mmol, 2.0 equiv.) in $1: 1(\mathrm{v} / \mathrm{v}) \mathrm{DMF} / \mathrm{MeCN}(3 \mathrm{~mL}$ total) was irradiated with $5 \mathrm{~W}$ blue LEDs at room temperature under argon for $24 \mathrm{~h}$. ${ }^{b}$ Isolated yields are provided. 'Acetals were not separated, and the subsequent removal of the acetal group was directly carried out, and the yield is the total yield of the two-step reaction.

compound (43\%). Carbonyl substituents were also tolerated: ketone- and ester-bearing phenylacetylene bromides yielded the corresponding products ( $3 \mathbf{u}$ and $3 \mathbf{v}$ ) in $30-45 \%$ yields. We also found that the presence of multiple $\mathrm{Cl}$ atoms on the benzene ring did not affect the yield; $3 \mathbf{w}$ was obtained in $40 \%$ yield. We also explored the reactivity of substrates in which the phenyl ring had been replaced by a heterocycle and found that electronrich thiophene $(3 \mathbf{x}, 34 \%)$ and indole $(3 \mathbf{z}, 40 \%)$ rings and an electron-deficient aromatic pyridine ring (3y, 56\%) were tolerated.

Alkenyl groups can also act as acceptors for acetal radicals, as reported by $\mathrm{Xu}^{10}$ and Wang. ${ }^{13}$ However, when we carried out the reaction between 2 and an olefin-containing substrate, we isolated (3aa, 43\%), which indicates that the olefin did not participate in the reaction. In addition, polycyclic product (3ab, $27 \%$ ) was prepared from a $\mathrm{Br}$-substituted derivative of estrone, which is a steroid hormone and an endogenous estrogen. We 
were also able to obtain $3 a c(30 \%)$ from a substrate derived from palmitic acid, which is an important component of blood lipids. The derivatization of these biologically relevant compounds indicates the potential utility of this protocol. Finally, when the products of the acetalation reactions of 1-(bromoethynyl)-3methylbenzene and 1-(bromoethynyl)-4-(tert-butyl)benzene were directly protonated, ${ }^{14}$ the corresponding hydroformylation products (3ad and 3ae) were obtained with yield of $48 \%$ and $32 \%$.

To gain insight into the reaction mechanism, we conducted some radical-trapping and radical-inhibition experiments (Scheme 3). When the reaction of alkynyl bromide $\mathbf{1 g}$ was carried out in the presence of the radical inhibitor TEMPO (2,2,6,6-tetramethylpiperidin-1-oxyl), no reaction occurred and none of the desired product was observed, a result that supports the involvement of radical intermediates (eq. (1)). In addition, the acetal radical could be trapped by ethene-1,1-diyldibenzene (eq. (2)), as confirmed by high-resolution mass spectrometry. Surprisingly, when $\mathbf{2}$ is omitted, $\mathbf{1} \mathrm{g}$ of debromination occurs in the presence of $\mathrm{Cs}_{2} \mathrm{CO}_{3}$ and a photocatalyst, which consumes a portion of the alkynyl bromide, wherein the terminal alkyne may be derived from less water in the solvent as its proton hydrogen source ${ }^{15}$ and it may be the main cause of low yield. Because terminal alkynes are known to act as radical acceptors, ${ }^{16}$ we wondered whether a terminal alkyne could undergo the acetalation reaction. To explore this possibility, we carried out two experiments with 1-ethynyl-4-phenylbenzene. When this substrate was subjected to the standard conditions, the acetalation reaction did not proceed (eq. (4)). However, when $N$ bromosuccinimide and $\mathrm{AgNO}_{3}$ were present in the reaction mixture (eq. (5)), $3 \mathrm{~g}$ was obtained in $52 \%$ yield, which confirms that an alkynyl bromide was the true reactive species.

On the basis of our mechanistic studies, we propose the mechanism outlined in Scheme 4. First, the metal-free photocatalyst $4 \mathrm{CzIPN}$ is photoexcited to 4 CzIPN* by irradiation with the $5 \mathrm{~W}$ blue LEDs. The cesium salt of 2,2-diethoxyacetic acid $\left(E_{\mathrm{ox}}=+0.95 \mathrm{~V} v s . \mathrm{SCE}\right)^{17}$ readily undergoes a single-electron transfer reaction with $4 \mathrm{CzIPN} *$ to form carboxyl radical intermediate $\mathbf{I}$. Intermediate $\mathbf{I}$ then loses a molecule of $\mathrm{CO}_{2}$ to form acetal radical II, which adds to arylethynyl bromide $\mathbf{1} \mathbf{g}$ to give

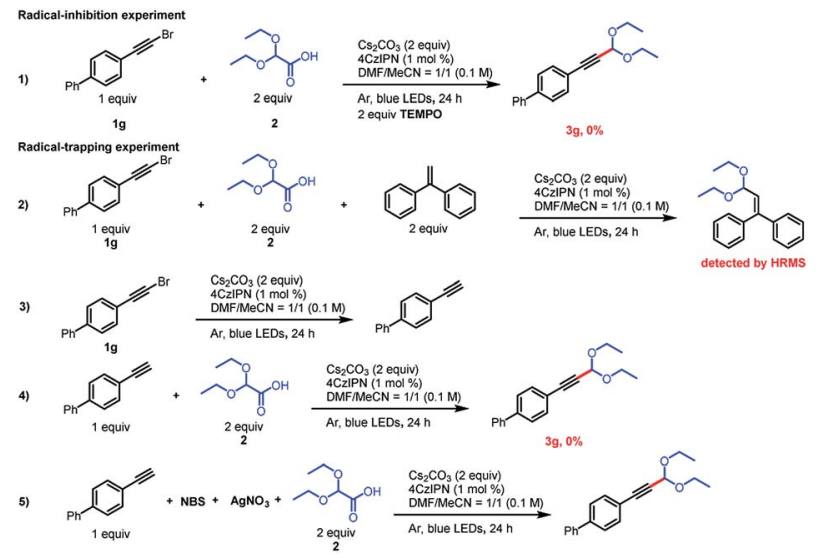

Scheme 3 Mechanistic experiments.

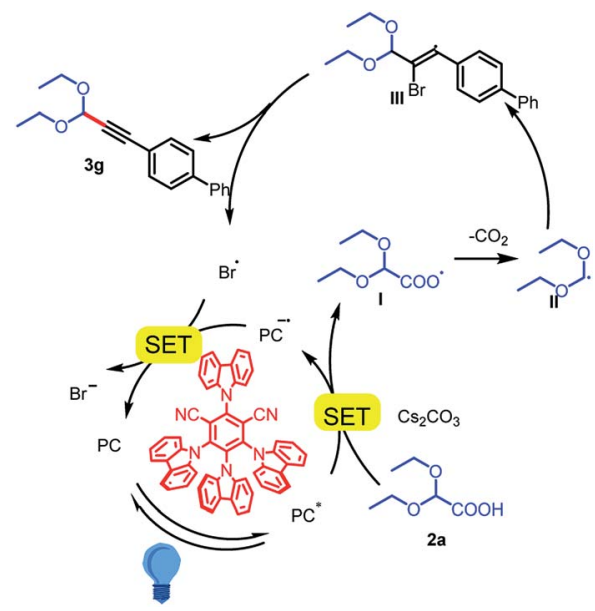

Scheme 4 Possible reaction mechanism.

stable bromoalkenyl radical III. ${ }^{18}$ Collapse of this radical gives product $3 \mathrm{~g}$ and a bromine radical. ${ }^{19}$ The bromine $\operatorname{radical}\left(E_{1 / 2}{ }^{\text {red }}\right.$ $\left[\mathrm{Br} / \mathrm{Br}^{-}\right]=+0.80 \mathrm{~V}$ vs. SCE in DME $)^{20}$ is reduced to a bromine anion by the reduced-state photocatalyst $\left(E\left[\mathrm{PC} / \mathrm{PC}^{\cdot-}\right]=-1.21 \mathrm{~V}\right.$ vs. SCE), ${ }^{12}$ which completes the catalytic cycle. However, we cannot exclude another mechanism involving alkynyl radicals, whose generation has been reported under similar conditions. ${ }^{21}$

\section{Conclusions}

In summary, we have developed a protocol for visible-lightpromoted acetalation of alkynyl bromides with readily available 2,2-diethoxyacetic acid as the acetal source. The alkynyl bromide substrates can be synthesized easily, and the acetalation reaction proceeds without the need for an additional oxidant and is therefore compatible with various functional groups. In addition to arylethynyl bromides, alkynyl bromides bearing heteroaryl rings (thiophene, pyridine, and indole) were also effective substrates.

\section{Conflicts of interest}

There are no conflicts to declare.

\section{Acknowledgements}

We are grateful to the National Key Research and Development Program of China (2018YFD0200100) and the National Natural Science Foundation of China (21732002, 21672117, 21772102) for generous financial support for our programs. The authors thank Yuanqiong Huang (Nankai University) for helpful discussion.

\section{References}

1 E. Lenci, G. Menchi, F. I. Saldívar-Gonzalez, J. L. MedinaFranco and A. Trabocchi, Org. Biomol. Chem., 2019, 17, 1037-1052. 
2 For compounds containing spiroacetal moieties, see: (a) A. F. Kluge, Heterocycles, 1986, 24, 1699-1740; (b) F. Perron and K. F. Albizati, Chem. Rev., 1989, 89, 1617-1661; (c) W. Francke and W. Kitching, Curr. Org. Chem., 2001, 5, 233-251; (d) M. A. Brimble and D. P. Furkert, Curr. Org. Chem., 2003, 7, 1461-1484; (e) J. E. Aho, P. M. Pihko and T. K. Rissa, Chem. Rev., 2005, 105, 4406-4440; $(f)$ S. Favre, P. Vogel and S. Gerber-Lemaire, Molecules, 2008, 13, 25702600; $(g)$ Y. K. Booth, W. Kitching and J. J. De Voss, Nat. Prod. Rep., 2009, 26, 490-525; (h) J. Sperry, Z. E. Wilson, D. C. K. Rathwell and M. A. Brimble, Nat. Prod. Rep., 2010, 27, 1117-1137; (i) R. Quach, D. F. Chorley and M. A. Brimble, Org. Biomol. Chem., 2014, 12, 7423-7432; (j) F.-M. Zhang, S.-Y. Zhang and Y.-Q. Tu, Nat. Prod. Rep., 2018, 35, 75-104. For compounds containing bridged bicyclic acetals moieties, see: D. J. Faulkner, Nat. Prod. Rep., 2002, 19, 1-49.

3 (a) E. M. Seward, E. Carlson, T. Harrison, K. E. Haworth, R. Herbert, F. J. Kelleher, M. M. Kurtz, J. Moseley, S. N. Owen, A. P. Owens, S. J. Sadowski, C. J. Swain and B. J. Williams, Bioorg. Med. Chem. Lett., 2002, 12, 25152518; (b) Y. Ohtake, T. Sato, T. Kobayashi, M. Nishimoto, N. Taka, K. Takano, K. Yamamoto, M. Ohmori, M. Yamaguchi, K. Takami, S.-Y. Yeu, K.-H. Ahn, H. Matsuoka, K. Morikawa, M. Suzuki, H. Hagita, K. Ozawa, K. Yamaguchi, M. Kato and S. Ikeda, J. Med. Chem., 2012, 55, 7828-7840; (c) L.-G. Milroy, G. Zinzalla, F. Loiseau, Z. Qian, G. Prencipe, C. Pepper, C. Fegan and S. V. Ley, ChemMedChem, 2008, 3, 1922-1935.

4 (a) T. W. Greene and P. G. M. Wuts, Protective Groups in Organic Synthesis, John Wiley and Sons, New York, 3rd edn, 1999; (b) P. J. Kocienski, Protecting Groups, George Thieme, Stuttgart, 1st edn, 1994.

5 (a) J. M. R. Narayanam and C. R. J. Stephenson, Chem. Soc. Rev., 2011, 40, 102-113; (b) J. Xie, H.-M. Jin and A. S. K. Hashmi, Chem. Soc. Rev., 2017, 46, 5193-5203; (c) J.-R. Chen, X.-Q. Hu, L.-Q. Lu and W.-J. Xiao, Chem. Soc. Rev., 2016, 45, 2044-2056; (d) C. K. Prier, D. A. Rankic and D. W. C. MacMillan, Chem. Rev., 2013, 113, 5322-5363; (e) P. Xu, W.-P. Li, J. Xie and C.-J. Zhu, Acc. Chem. Res., 2018, 51, 484-495.

6 For selected papers, see: (a) J. Xuan, Z.-G. Zhang and W.-J. Xiao, Angew. Chem., Int. Ed., 2015, 54, 15632-15641; (b) K. L. Skubi, T. R. Blum and T. P. Yoon, Chem. Rev., 2016, 116, 10035-10074; (c) M. Rahman, A. Mukherjee, I. S. Kovalev, D. S. Kopchuk, G. V. Zyryanov, M. V. Tsurkan, A. Majee, B. C. Ranu, V. N. Charushin, O. N. Chupakhin and S. Santra, Adv. Synth. Catal., 2019, 361, 2161-2214; (d) Y.-F. Liang, X.-H. Zhang and D. W. C. MacMillan, Nature, 2019, 559, 83-88; (e) J. A. Kautzky, T. Wang, R. W. Evans and D. W. C. MacMillan, J. Am. Chem. Soc., 2018, 140, 6522-6526; $(f) \quad$ N. A. Till, R. T. Smith and D. W. C. MacMillan, J. Am. Chem. Soc., 2018, 140, 57015705; (g) C. Zheng, W.-M. Cheng, H.-L. Li, R.-S. Na and R. Shang, Org. Lett., 2018, 20, 2559-2563; (h) R. Shang and L. Liu, Sci. China: Chem., 2011, 54, 1670-1687; (i) Z. Huang, R. Shang, Z.-R. Zhang, X.-D. Tan, X. Xiao and Y. Fu, J. Org.
Chem., 2013, 78, 4551-4557; (j) B. Zhao, R. Shang, W.-M. Cheng and Y. Fu, Org. Chem. Front., 2019, 5, 17821786.

7 For selected papers, see: (a) Z.-W. Zuo, H. Cong, W. Li, J. Choi, G. C. Fu and D. W. C. MacMillan, J. Am. Chem. Soc., 2016, 138, 1832-1835; (b) J. D. Griffin, M. A. Zeller and D. A. Nicewicz, J. Am. Chem. Soc., 2015, 137, 11340-11348; (c) L. Candish, L. Pitzer, A. Goméz-Suárez and F. Glorius, Chem.-Eur. J., 2016, 22, 4753-4756; (d) L. Candish, E. A. Standley, A. Goméz-Suárez, S. Mukherjee and F. Glorius, Chem.-Eur. J., 2016, 22, 9971-9974; (e) A. Millet, Q. Lefebvre and M. Rueping, Chem.-Eur. J., 2016, 22, 13464-13468.

8 For selected papers, see: (a) W.-M. Cheng, R. Shang and Y. Fu, ACS Catal., 2017, 7, 907-911; (b) A. Fawcett, J. Pradeilles, Y. Wang, T. Mutsuga, E. L. Myers and V. K. Aggarwal, Science, 2017, 357, 283-286; (c) R. S. J. Proctor, H. J. Davis and R. J. Phipps, Science, 2018, 360, 419-422; (d) M.-C. Fu, R. Shang, B. Zhao, B. Wang and Y. Fu, Science, 2019, 363, 1429-1434; (e) C. Jin, Z.-Y. Yan, B. Sun and J. Yang, Org. Lett., 2019, 21, 2064-2068.

9 W.-G. Kong, C.-J. Yu, H.-J. Anand and Q.-L. Song, Org. Lett., 2018, 20, 349-352.

10 S. Zhang, Z.-M. Tan, H.-N. Zhang, J.-L. Liu, W.-T. Xu and K. Xu, Chem. Commun., 2017, 53, 11642-11645.

11 (a) H.-C. Huang, G.-J. Zhang and Y.-Y. Chen, Angew. Chem., Int. Ed., 2015, 127, 7983-7987; (b) H.-C. Huang, G.-J. Zhang, L. Gong, S.-Y. Zhang and Y.-Y. Chen, J. Am. Chem. Soc., 2014, 136, 2280-2283; (c) X.-S. Liu, Z.-T. Wang, X.-M. Cheng and C.-Z. Li, J. Am. Chem. Soc., 2012, 134, 14330-14333.

12 (a) J. Luo and J. Zhang, ACS Catal., 2016, 6, 873-877; (b) H. Uoyama, K. Goushi, K. Shizu, H. Nomura and C. Adachi, Nature, 2012, 492, 234-238; (c) T.-Y. Shang, L.-H. Lu, Z. Cao, Y. Liu, W.-M. He and B. Yu, Chem. Commun., 2019, 55, 5408-5419.

13 H. Huang, C.-G. Yu, Y.-T. Zhang, Y.-Q. Zhang, P. S. Mariano and W. Wang, J. Am. Chem. Soc., 2017, 139, 9799-9802.

14 The accomplishment of protonization see ESI. $\dagger$

15 M. Zhao, C.-X. Kuang, Q. Yang and X.-Z. Cheng, Tetrahedron Lett., 2011, 52, 992-994.

16 (a) H. Jiang, Y.-Z. Cheng, Y. Zhang and S.-Y. Yu, Org. Lett., 2013, 15, 4884-4887; (b) S. Sumino, M. Uno, T. Fukuyama, I. Ryu, M. Matsuura, A. Yamamoto and Y. Kishikawa, J. Org. Chem., 2017, 82, 5469-5474.

17 H. Huang, X.-M. Li, C.-G. Yu, Y.-T. Zhang, P. S. Mariano and W. Wang, Angew. Chem., Int. Ed., 2017, 56, 1500-1505.

18 (a) Z.-Y. Song, C.-L. Zhang and S. Ye, Org. Biomol. Chem., 2019, 17, 181-185; (b) J.-J. Zhang, P.-H. Li and L. Wang, Org. Biomol. Chem., 2014, 12, 2969-2978.

19 L. Eberson, M. P. Hartshorn, J. J. McCullough, O. Persson and F. Radner, Acta Chem. Scand., 1998, 52, 1024-1028.

20 V. Bacauanu, S. Cardinal, M. Yamauchi, M. Kondo, D. F. Fernández, R. Remy and D. W. C. MacMillan, Angew. Chem., Int. Ed., 2018, 57, 12543-12548.

21 (a) Y.-C. Zhao, J.-W. Jin and P. W. H. Chan, Adv. Synth. Catal., 2019, 361, 1313-1321; (b) K. Ni, L.-G. Meng, K. Wang and L. Wang, Org. Lett., 2018, 20, 2245-2248. Another proposed mechanism see ESI. $\dagger$ 